\title{
The Risk Factors of Adolescent Depression
}

\author{
Sia Agarwal \\ Valley Christian High School, 100 Skyway Dr \#130, San Jose, CA 95111, USA; sia1991agarwal@gmail.com
}

ABSTRACT: The identification of potent risk factors is crucial to potentially prevent and intervene in adolescent depression. Conducting a literature search about the risk factors for adolescent depression in Google Scholar, BioMed Central, Nature, Pubmed, APA PsycNet, Science Direct, I included articles if the study discussed or measured risk factors of depression in a sample of individuals ages 10 to 19 . The genetic, sex, stress, cognitive, gender, and interpersonal risk factors of adolescent depression are reviewed. Certain genetic mutations, negative inferential style, having a depressed parent, being a girl, and experiencing a recent stressful life event emerged as the most potent risk factors of adolescent depression. Understanding these risk factors and targeting them could lead to more effective adolescent depression prevention and interventions.

KEYWORDS: Behavioral and Social Sciences; Clinical and Developmental Psychology; Adolescent Depression; Depression Interventions.

\section{Introduction}

Because adolescents, who are individuals ages 10 to 19 , are especially vulnerable to the risk of depression, identifying risk factors - characteristics often correlated with depression - will lead to more efficient interventions. ${ }^{1}$ Intervention can be most effective when risk factors are appropriately identified and targeted. $^{2}$

This paper discusses the gender, cognitive, interpersonal, and chronic and acute stress factors of adolescent depression. The review concludes with a proposal of methods to target the strongest predictors of adolescent depression.

\section{- Discussion \\ What is Depression?}

The American Psychiatric Association defines depression as a medical disorder that affects an individual's thinking, feelings, and behavior. Loss of enjoyment in usually enjoyable activities along with prolonged feelings of low mood constitutes the nature of depression. ${ }^{3} \mathrm{~A}$ doctor must note that a patient exhibits at least five symptoms out of Diagnostic and Statistical Manual of Mental Disorders (DSM-5) to diagnose the individual with depression. To fulfill the requirements of a diagnosis of depression, symptoms must persist for at least two weeks. ${ }^{4}$ Symptoms of depression include dejected mood, prolonged feelings of sadness, frequent feelings of lethargy, sleeping problems, loss in interest in usually enjoyable activities, and difficulties in concentrations and making decisions. ${ }^{5}$

Researchers and doctors use screening scales to effectively measure and identify symptoms of depression in individuals. ${ }^{6}$ Scales include the Beck Depression Inventory (BDI), the Center for Epidemiological Studies Depression Scale for Children (CES-DC), Centers for Epidemiologic Study Depression (CESD) Scale, Hamilton Depression Rating Scale (HAM-D), the Children's Depression Inventory (CDI), and the Behavior Assessment System for Children (BASC). ${ }^{7}$

\section{- Methods}

To determine which risk factors to discuss, I reviewed literature from Google Scholar, BioMed Central, Nature Journal, Pubmed, APA PsycNet, Science Direct, and Google searches. Some of the search terms I used were the following: 'genetic influences depression in adolescents', 'genetic predisposition to depression intervention', 'individual sex risk factor adolescent depression', 'biological sex risk factor adolescent depression', 'gender stereotypes effect on adolescent depression', 'negative attributional style adolescent depression', 'family functioning adolescent depression', 'peer relationships adolescent depression', and 'exposure to stress depression ad olescents'.

Because the study of emotional disorders involves biological, psychological, and social influencing factors, I included risk factors from each of these categories; these decisions were supported by their prevalence in existing scientific literature. ${ }^{2}$ I included articles on risk factors if the article studied individuals ages 10 to 19 and examined adolescent depression.

\section{Prisma:}

PRISMA (Preferred Reporting Items for Systematic Reviews and Meta-Analyses) is a set of items reported in a systematic review. Below is a modified version of the PRISMA set. This review is not systematic.
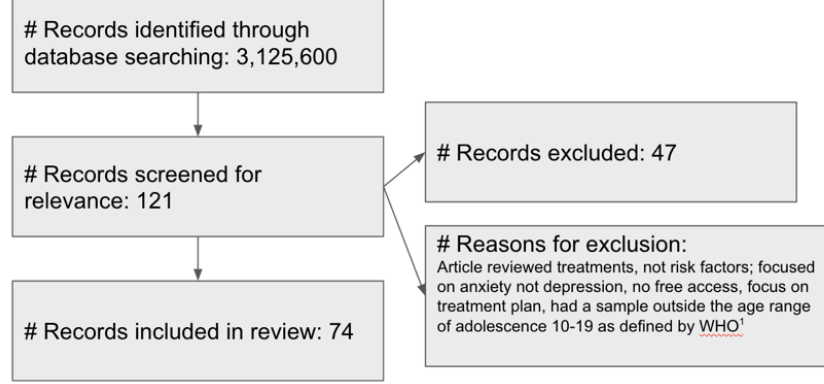


\section{Biological Factors:}

Sex and genetics are the biological factors most associated with adolescent depression in existing scientific literature. I chose to review these two factors as risk factors based on their prevalence in the literature review.

\section{Psychological Factors:}

I included gender due to the extensively researched difference in depression rates between boys and girls. I also included a range interpersonal factors; the condition of social relationships is an indicator of psychological well-being. ${ }^{8}$

\section{Risk Factors of Adolescent Depression:}

\section{Biological Factor-Genetics:}

Research estimates that $40 \%$ of adolescent depression is related to inherited genes. ${ }^{9}$

\section{5-HTT:}

The 5-HTT gene codes for a serotonin transporter. ${ }^{10}$ The short allele, or the S allele, of 5-HTT is related to depression in adolescents. ${ }^{11}$ Hankin et al. found that individuals with the $\mathrm{s} / \mathrm{s}$ genotype tested for the highest scores of depression in a sample of 220 adolescents as they experienced external stressors. interacted with external stressors. ${ }^{12}$ Another study, Benjet et al., found that the interaction between the 5-HTT gene and peer stress predicted for higher levels of depressive symptoms in adolescent girls. ${ }^{13}$ It was further concluded that adolescent girls with the s/s genotype were the most vulnerable to depressive symptoms because of peer stress. Girls with two short alleles and experiences of bullying scored higher on the study's depression screening measure than girls who had the same genotype but no experiences of peer stress.

To understand the strength of 5-HTT as a risk factor of adolescent depression, it is necessary to consider the frequency of 5-HTTLPR genotypes in the adolescent population. In a sample of 309 adolescents from Wisconsin, Priess-Groben and Hyde found "[ $\mathrm{f}$ ]requencies of 5-HTTLPR...were 34.6 $\%$ long/long, $46.8 \%$ long/short, and $18.6 \%$ short/short" ${ }^{11}$ In another sample, genetic frequencies of "5-HTTLPR were $33 \% \mathrm{~L} / \mathrm{L}, 46 \% \mathrm{~S} / \mathrm{L}$, and $21 \% \mathrm{~S} / \mathrm{S}$ ". ${ }^{12}$

\section{Brain-derived neurotrophic factor (BDNF:}

The Brain-derived neurotrophic factor (BDNF) gene codes for the protein that maintains neuron survival by regulating growth, maturation, and cell repair/maintenance. ${ }^{14}$ The BDNF Val66Met gene is a polymorphism where valine (Val) is replaced with methionine (Met) at codon 66 in the genetic sequence. Emotional and cognitive dysfunction is associated with this polymorphism; the polymorphism causes alterations in grey matter and modifies glutamate receptor activities. ${ }^{15}$ The average frequency of this polymorphism across a sample of populations in one study was $19.6 \% .{ }^{16}$ Comasco et al. observed the interaction effect of 5-HTTLPR, negative early life events, and BDNF Val66Met in a sample of 1393 adolescents and found that adolescents with the ss/sl+Val/Val or the 11+Met genotypes had more depressive symptoms than those without. ${ }^{17}$

\section{Biological Factor - Sex :}

Biological sex can be observed at the genetic, hormonal, anatomical and behavioral levels. As sex differentiation occurs in adolescence, it can lead to the risk of depressive disorders. ${ }^{18}$

\section{Hormones:}

The HPA axis (hypothalamic-pituitary-adrenal axis) is a neuroendocrine system that consists of the hypothalamus, the pituitary gland, and the adrenal glands. It serves the key role in the body's reaction to stress. ${ }^{19}$ As the HPA axis develops during adolescence, certain pathways begin to produce hormones, such as estrogen and testosterone. ${ }^{18}$

Estrogen increases the transport and uptake of serotonin. During puberty, the homeostasis of estrogen is disrupted. Due to the consequential disruption of estrogen levels, adolescent girls are more vulnerable to mood disorders such as depression. Low levels of estrogen are related to depression. ${ }^{20}$

On the other hand, the hormone testosterone functions in both males and females. ${ }^{21}$ However, the effects of testosterone for boys and girls differ. For girls, high levels of testosterone are correlated with depression; for boys, low levels of testosterone are correlated with depression. ${ }^{22}$

\section{Psychological factor - Stress :}

Stress can trigger the onset of depression, according to the Hopelessness Theory of Depression. There are different types of stressors: acute, episodic acute, and chronic stressors. ${ }^{23}$

Acute stress occurs after a single particularly stressful event; symptoms of acute stress develop in a short time period (minutes to hours) after the individual experiences the stressor. ${ }^{24}$ Episodic acute stressors are several, continued experiences of acute stressors, resulting in episodes of acute stress over a period of time. ${ }^{23}$ Chronic stress is stress that persists over time; because of its unrelenting nature, many people acclimate themselves to the the symptoms of chronic stress, especially if the stress is a result of the individual's mindset or strenuous circumstances. ${ }^{23}$ This section discusses stressful life events, which can be acute stressors or episodic stressors, and daily life or chronic stressors.

\section{Stressful Life Events :}

Stressful life events (SLEs) can trigger the onset of adolescent depression. Severely stressful life events include physical abuse, assault, and emotional abuse. Other stressful life events are parents' divorce or moving to a new home or school. ${ }^{25}$ Since "approximately $70 \%$ of first depressive episodes and $40 \%$ of recurrent episodes of depression are preceded by a severe stressful life event" ${ }^{\text {"26 }}$, SLEs should be seriously considered as a risk factor for adolescent depression. Interventions can screen for SLEs to identify those at a greater risk for adolescent depression.

One type of SLE is an adverse childhood experience (ACE). The CDC states that ACEs "are potentially traumatic events that occur in childhood (0-17 years)" ${ }^{27}$ In a sample of 288 Native American adolescents and young adults (sample mean age $=19.25)$, Brockie et al. measured ACEs and depressive symptoms via a 189 -question questionnaire. ${ }^{28}$ The questionnaire assessed six childhood traumatic events: "physical abuse, emotional abuse, sexual abuse, emotional neglect, physical neglect, and witnessing violence against mother." An assessment of depressive symptoms associated with ra cial discrimination and historical loss were also included in this questionnaire. ${ }^{28}$ Based on the questionnaire's results, the researchers found that with every additional instance of an $\mathrm{ACE}$, there was a 
$57 \%$ increase of depressive symptoms. Not including sexual abuse, the ACEs measured predicted for de pressive symptoms. Out of the six ACEs assessed, physical abuse correlated most strongly with depressive symptoms. Those with experiences of 3-6 ACEs had four and half times chances of depressive symptoms compared to those experiences of 0-2 ACEs. ${ }^{28}$ Another study, Schilling et al., measured ACEs and depressive symptoms in a sample of 1093 high school seniors using a modified version of the CESD and a series of questions to assess ACEs. ${ }^{29}$ Similar to Brockie et al., Schilling et al. concluded that depressive symptoms increased with each additional ACE. ${ }^{29}$

\section{Chronic Stressor: Daily Stressors and Common Life Difficul-} ties:

A 2014 APA survey of 1018 adolescents, ages 13-17, reported that $30 \%$ of surveyed adolescents felt depressed due to stress; additionally, $31 \%$ of surveyed individuals also reported that their stress levels have increased in the past year and that they feel stress will continue to increase. ${ }^{30}$

Daily or common stressors for adolescents usually include school, extra-curriculars, and family responsibilities. Overloading of assignments, social pressure, academic performance pressure, and peer competition contribute to school-related stress. One study, Jayanthi et al., found that adolescents who reported academic stress were at a 2.4 higher risk of depression than those who did not report academic stress. ${ }^{31}$ Low et al. studied associations between common stressors and mental health impacts in a sample of 1025 adolescents, ages 11 to 15 , and found similar results in the relationship between depressive symptoms and stress from school work. ${ }^{25}$ These studies suggest that chronic academic stress could be a risk factor in adolescent depression.

\section{Psychological factor - Cognitive Style:}

A cognitive style is a pattern of thinking that deals with attention, memory, and other vital cognitive functions. In childhood, cognitive styles begin to form, stabilizing and influenced by external factors during adolescence. ${ }^{32}-34$ A negative cognitive style, also called a negative attributional or inferential style, refers to how individuals continually assign the cause of negative events to internal, stable, and global causes.33,35 Three dimensions constitute an attributional style: "internal vs. external (whether attributions relate to causes inside or outside the self), stable versus unstable (whether attributions are for causes that persist with time or not), and global versus specific (whether attributions affect many or few situations)" ${ }^{36}$ Individuals with a negative inferential style assume that their personal characteristics are negative and unfixable because of these attributions. ${ }^{37}$ Individuals whose attributional styles are internal, stable, and global are more likely to be at risk to depression. $^{36}$

An example of a negative inferential style can operate like so: An individual attributes the cause of the end of a friendship to their own fault (self). They then infer that all this circumstance will always be the case for their friendships (stability). Finally, they infer that this would affect their future and all relationships of this nature (global).

Research suggests that a negative cognitive style is a strong predictor of adolescent depression. Rohde et al. tested several risk factors of adolescent depression ("depressive symptoms, past MDD, hopelessness, negative cognitions, negative attributional style, poor self-esteem, loneliness, low social support, negative life events, poor social adjustment, substance use, low motivation to reduce depression, sex, race/ethnicity, age, and socioeconomic status") and found that the strongest predictor of adolescent depression in that sample was a negative inferential style. The group of adolescents with high negative inferential style scores were at four times more risk of depression than those who did not have negative attributional styles. ${ }^{38}$ Muris et al. supports the correlation between a negative attributional style and adolescent depression with a model that showed negative attributional styles as the main source of depression in their sample. ${ }^{39}$

Negative attributional style coupled with other cognitive vulnerabilities can also cause risk of adolescent depression. One study, Southall and Roberts, found that self-esteem moderates the degree to which an adolescent with a negative attributional style is at risk of depression. ${ }^{40} \mathrm{~A}$ moderate correlation was discovered between low self-esteem and a negative attributional style, putting adolescents with both at a greater risk for depression than adolescents without either. ${ }^{40}$ High self-esteem could act as a protective factor against the effects of a negative attributional style on depression because it prevents the spiraling towards general hopelessness. High esteem provides resilience against times of stress for individuals with negative attributional style. The development of depressive symptoms is avoided in this manner. This combination of high self-esteem with a negative attributional style may be a result of an unconditional positive self-regard. ${ }^{41}$ The protective nature against depression of high self-esteem could be explored in cognitive behavioral therapies for depression interventions.

\section{Cognitive Style and Stress:}

When a negative cognitive style interacts with stress, it can contribute to depression, as put forth by the cognitive-diathesis stress model. ${ }^{37}$ The Hopelessness Theory of Depression adds to this model by proposing that individuals with negative inferential styles react to negative life events with hopelessness. ${ }^{19}$ These kinds of attributions, especially if repeated due to multiple occurrences of the stressful event, increase risk of depression. $^{33}$

Hankin et al. tested the Hopelessness Theory by observing the interactions of different negative inferential styles with stress and comparing the resulting depressive symptoms. ${ }^{34}$ In a sample of 350 adolescents, the researchers measured negative inferential styles and depressive symptoms with the Adolescent Cognitive Style Questionnaire (ACSQ); stressful life events were also recorded. The study found that for individuals with highly negative inferential styles, levels of depressive symptoms increased as stress increased. Those who did not have negative inferential styles coped better with stress and did not have high levels of depressive symptoms as a result of their inferential style. ${ }^{34}$

While some do not, some adolescents may actively contribute to the amount of stress in their life. The stress generation framework posits that adolescents actively contribute to the amount of stress in their life due to specific types of behavior. ${ }^{42}$ Before the beginning of a stressful event, pre existing 
frameworks of thinking, such as an adolescent's expectations, perceptions, and interpretations influence the reaction to stress. These cognitive styles are established more firmly during adolescence. ${ }^{34}$ Furthermore, adolescents with higher levels of cognitive vulnerability, such as negative cognitive style, self-criticism, and dependency, contribute to more stress in their life, which in turn means higher levels of depressive symptoms. $^{43}$

\section{Interpersonal stress and cognitive styles:}

A negative cognitive style can also affect how an individual perceives interpersonal interactions. Lee et al. concluded adolescents who possessed a negative cognitive style were more affected by negative parental interactions in terms of depression levels. ${ }^{44}$ Ongoing negative interactions in relationships, coupled with negative perceptions of life situations, can put an adolescent at risk to depression. ${ }^{44}$

Peer relationships can also influence who has a negative attributional style. In friendships, adolescents whose close friends had negative attributional styles were more likely to have negative attributional styles, and subsequently, were more likely to exhibit depressive symptoms. ${ }^{45}$

Identifying the types of stress that exacerbate the use of negative attributional styles, and therefore increase risk to depression, may be useful in the construction of effective depression interventions.

Gender differences in negative cognitive styles and implications for depression:

For both female and male adolescents, depression is correlated with higher levels of a negative attributional style. However, research suggests that girls and boys differ in their types of attributional styles. Gladstone et al. found that boys were more likely to have depressogenic attributions in the stable dimension; this means that boys were more likely to attribute the cause of a negative event to stable causes than girls. ${ }^{46} \mathrm{On}$ the other hand, girls were more likely to have depressogenic attributions in the global dimension, meaning that the cause of a negative event would affect all situations of a similar nature. Girls made more internal attributions than boys; this behavior correlated with their overall lower self-esteem compared to boys. As mentioned before, lower self-esteem is also correlated with adolescent depression. The gender differences in types of negative attributions may relate to the differences in depression rates between boys and girls. ${ }^{46}$

In summary, negative cognitive styles can interact with stress to form cognitive vulnerabilities to depression in adolescents. Identifying individuals with negative attributional styles, perhaps by using the Adolescent Cognitive Style Questionnaire, could prove useful in interventions that target cognitive styles. Cognitive behavioral therapies focus on negative inferential styles, which are a strong predictor of depression, and they are effective at shifting these styles to more positive patterns of thinking. Thus, interventions should consider targeting cognitive styles for efficacy in reducing adolescent depression levels.

\section{Social factor-Gender:}

Gender is defined as the social constructs of the characteristics of girls and boys. Behaviors and roles are associated with certain genders, affecting how individuals view themselves and experience the world. ${ }^{48}$

Boys and girls are at different levels of risk of depression and experience depression differently. Girls are twice more likely to develop depression in adolescence than boys. ${ }^{49}$

Boys and girls exhibit depression differently. In a sample of 383 adolescents, Bennett et al. measured depressive symptoms with the Childhood Version of the Schedule for Affective Disorders and Schizophrenia and the BDI.50 From their trial, they concluded that girls' depressive symptoms could be described by higher levels of excessive guilt, self-blame, dissatisfaction, "self-disappointment, feelings of failure, concentration problems, difficulty working, sadness or depressed mood, sleep problems, fatigue". ${ }^{50}$ Depression in boys appeared as symptoms of "anhedonia, depressed morning mood, and morning fatigue". ${ }^{0}$ Another study, Khesht-Masjedi et al., measured depressive symptoms in a sample of 191 adolescents and found similar results. ${ }^{51}$ In this sample, depressed girls experienced more guilt, self-blame, and dissatisfaction whereas boys experienced more trouble sleeping and fatigue. ${ }^{51}$ Seeley et al. screened for a number of risk factors for depression (parent and peer support, negative life events, attributional style, emotionality, perfectionism, body dissatisfaction, bulimic symptoms, physical activity, social adjustment, delinquency, substance use) in a sample of 479 adolescent girls. ${ }^{52}$ They found that the strongest predictors of depression in this sample were delinquency, poor school and familial functioning, subclinical depressive symptoms, minimal parental support, and symptoms of bulimia. The highest risk group were girls who had both elevated depressive symptoms and poor academic performance; they marked a $40 \%$ incidence of major depression. ${ }^{52}$

The stress of social pressure that girls and boys face to conform to gender roles may be a risk factor to depression. As they move into adolescence, girls may face real or perceived reduction in choices or opportunities. Reports from adolescents show that girls perceive more expectations and restrictions from their parents as compared to boys. Girls also may feel restricted by the types of activities and preferences that are deemed 'suitable' for girls by social norms. Such restrictions could be a source of chronic stress for adolescent girls. ${ }^{53}$ The mediational--stress exposure model posits that girls' rates of depression are higher due to their greater exposure of stress compared to boys. ${ }^{54}$ Girls experience greater exposure to interpersonal stress from peers, romantic partners, and family members. Reports of higher stress are not limited to the interpersonal domain. ${ }^{55}$

In addition to the differences in exposure to stress, girls and boys react differently to stress. The moderation-stress model posits that girls react more strongly to stressors in a way that puts them at a greater risk for depression. ${ }^{56}$ For example, girls are more likely to respond to stress with rumination, meaning they are more likely to dwell on the stressful situation without taking steps to relieve or eliminate stress. ${ }^{53}$ Rumination is a type of thinking pattern that focuses on negative content from the past and present. This type of thinking can be a cognitive vulnerability to adolescent depression. ${ }^{57}$ 
Depression in parents, especially mothers, is associated with negative parenting styles including rejection, high levels of criticism, and minimal acceptance, comfort, and/or warmth. These types of parenting styles strongly correlate with depression in their adolescents. ${ }^{61}$ Weissman et al. found that adolescents of depressed parents are three times more likely to develop depressive and anxiety disorders than those of non-affected parents. ${ }^{62}$ Between ages 15-20, adolescents of depressed parents were more likely to experience the onset of depression. ${ }^{62}$ Rice et al. found similar results: Children of depressed parents are at three to four times more risk of depression than children of healthy parents. ${ }^{9}$

Depression in parents is correlated with cognitive vulnerabilities to depression in adolescents. This includes higher levels of self-blame, usage of a negative attributional style, and lower self-worth. While each of these behaviors by themselves might not automatically lead to depression, they can be risk factors to developing depression later on. Depression in parents has also been correlated with poor interpersonal functioning, which in itself can be a risk factor to adolescent depression. Finally, depression in parents can also be a risk for the following: earlier age of onset, longer duration, greater functional impairment, higher likelihood of recurrence. ${ }^{61}$

\section{Family relationships:}

Parents play a vital role in an adolescent's development. ${ }^{63}$ Conflict within the parent-adolescent relationship and in the family may become a stressor for adolescents. Specifically, it may become a chronic stressor due to adolescent's inability to remove themselves from their family environment. ${ }^{64}$

The state of family functioning can also be a risk to adolescent depression. Family functioning can be described as composed of elements such as family structure, family communication, adaptability and cohesion, and problem solving. ${ }^{65}$

Rawatlal et al., found that adolescents who reported high levels of family dysfunction were more likely report depressive symptoms. ${ }^{66}$ Certain behaviors of the adolescent and parents may worsen the risk of depression. Constrained parental aggressiveness is correlated with adolescent depression. For girls, maternal submissiveness is correlated with depression. ${ }^{64} \mathrm{On}$ the other hand, there are also positive behaviors that can act as a buffer against depression. One example is emotional clarity, which is defined as the ability of an individual to accurately identify and understand their emotions. Over an observation period of 2 years, Freed et al. found that emotional clarity in adolescents acted as a protective factor against depressive symptoms and poor family functioning. ${ }^{67}$ The relationship that exists between depression and family functioning could be explained by the degree to which adolescents are able to exercise emotional clarity. A cycle may occur when poor emotional clarity degrades family relationships, which may subsequently cause depressive symptoms over an extended period of time. The study suggested that "it is possible that poor family functioning exacerbates depression and impaired emotion regulation for youth who already experience these deficits". ${ }^{67}$

\section{Peer relationships:}

Adolescents put more importance on peer relationships than any others, which sets the stage for greater exposure to inter- personal incidents and possible higher levels of reactivity to such stressors. ${ }^{68}$

Peer relationships can vary from dyadic relationships, a small group, or a large group of peers. These function as different social units. The dimensions of a social unit include social interactions, social support, and liking. Difficulties in peer relationships can include rejection, lack of perceived support from friends, and lack of popularity. ${ }^{69}$ Dysfunction in peer relationships may put an adolescent at risk to depression. In a sample of 143 adolescents, ages 13-14, Allen et al. found that "behavior undermining relatedness with close friends, calls for emotional support from close friends, and social withdrawal" strongly correlated with future depressive symptoms. ${ }^{69}$ Social withdrawal may be a particularly potent risk factor to depression because withdrawal isolates the adolescent from getting help they need to navigate changing relationship expectations. Withdrawal also causes long term effects when the individual does not know how to cope with new interpersonal changes or is left out interpersonal interactions entirely due to previous absence. For adolescents already diagnosed with depression, Armsden et al. supported the finding that depression is related to less secure peer attachment. ${ }^{70}$ Another study, Joiner, found a similar result that higher levels of depression in adolescents are correlated with higher levels of social withdrawal. ${ }^{71} \mathrm{Un}$ dermining behaviors of anger and hostility that are related to adolescent depression could provide a starting point for interventions for depression.

\section{Peer relationships:}

Peer victimization, consistent exposure of negative behaviors from peers, is associated with adolescent depression. ${ }^{72} \mathrm{Klomek}$ et al. measured the relationship between depressive symptoms and peer victimization in 2,342 high school students, ages 13 to 19 , using the BDI and a peer victimization questionnaire. ${ }^{73}$ They found that as rates of types of peer victimization increased, those individuals' depression rates increased. For male participants who experienced 5-6 types of victimization, there was a $29.7 \%$ prevalence of depression; for female participants who experienced 5-6 types of victimization, there was a $65.0 \%$ prevalence of depression. The more types of peer victimization a participant experienced, the more at risk they were to depression. ${ }^{73}$

\section{Conclusion}

The findings of this paper suggest that the strongest indicators and risk factors of adolescent depression are genetics, being a girl, a negative inferential style, having a depressed parent, and experiencing a recent stressful life experience. First, $40 \%$ of depression cases can be linked to genetics. Second, girls are 2 times more likely to develop depression in adolescence. Second, an adolescent with a depressed parent is 3 to 4 times more likely to develop depression compared to children with healthy parents. Third, having a highly negative inferential style puts an adolescent at four times the risk of depression than an adolescent with a healthy inferential style. Finally, "approximately $70 \%$ of first depressive episodes and $40 \%$ of recurrent episodes of depression are preceded by a severe stressful life event", making SLEs a significant risk factor to adolescent depression. ${ }^{27}$ These five make up the risk factors that are the most 
correlated with adolescent depression based on this literature review.

An effective intervention for adolescent depression could screen for four identified risk factors: female gender, a negative inferential style, having a depressed parent, and recent SLEs. Genetic screening is still possible, but it is more expensive. The intervention could resemble a psychoeducational intervention, such as the Coping with Depression Course, with modifications. ${ }^{74}$ First, a participant would be taken through a screening process; then, they would be directed to a risk-factor specific course that would help them with their specific issues. This way, high-risk groups could be identified by the screening measures and be given problem-specific skill training to help them prevent future depression or cope with current depressive symptoms. Future research could determine whether screening for risk factors before treatment is effective in reducing depressive symptoms or preventing depression. Future research could also look at whether an electronic delivery or an in-person of this program is more effective; electronic deliveries of interventions may be worthwhile researching because of global circumstances such as COVID-19.

\section{- Acknowledgements}

I want to thank Dr. Ethan Hutt for his guidance and support through the research process. Thank you for reviewing multiple drafts of my paper, encouraging me to keep researching and writing, and providing valuable feedback.

\section{References}

1. Adolescent health. (n.d.). Retrieved November 1, 2020, from Who. int website: https://www.who.int/southeastasia/health-topics/ adolescent-health

2. Risk and Protective Factors https://www.samhsa.gov/sites/default/ files/20190718-samhsa-risk-protective-factors.pdf (accessed Oct 26, 2020).

3. Depression (major depressive disorder) https://www.mayoclinic. org/diseases-conditions/depression/symptoms-causes/syc20356007 (accessed Oct 26, 2020)

4. Depression Diagnosis https://www.webmd.com/depression/guide/ depression-diagnosis (accessed Oct 26, 2020).

5. Torres, F. What Is Depression? https://www.psychiatry.org/ patients-families/depression/what-is-depression (accessed Oct 26, 2020).

6. Vahle, V. L. Depression Measures in Outcomes Research. Physical Medicine 2000, 81, S53-S62. https://doi.org/10.1053/ apmr.2000.20625.

7. Depression Assessment Instruments https://www.apa.org/ depression-guideline/assessment (accessed Oct 26, 2020).

8. Majd Ara, E.; Talepasand, S.; Rezaei, A. M. A Structural Model of Depression Based on Interpersonal Relationships: The Mediating Role of Coping Strategies and Loneliness. Noro 2017, 54 (2), 125130. https://doi.org/10.5152/npa.2017.12711.

9.Rice, F.; Harold, G.; Thapar, A. The Genetic Aetiology of Childhood Depression: A Review. J. Child Psychol. Psychiatry 2002, 43 (1), 65-79.

10.Bernaras, E.; Jaureguizar, J.; Garaigordobil, M. Child and Adolescent Depression: A Review of Theories, Evaluation Instruments, Prevention Programs, and Treatments. Frontiers in Psychology 2019, 10.

11.Priess-Groben, H. A.; Hyde, J. S. 5-HTTLPR X Stress in Adolescent Depression: Moderation by MAOA and Gender. Journal of Abnormal Child Psychology 2012, 41 (2), 281-294.
12.Hankin BL, Jenness J, Abela JR, Smolen A. Interaction of 5-HTTLPR and idiographic stressors predicts prospective depressive symptoms specifically among youth in a multiwave design. J Clin Child Adolesc Psychol. 2011;40(4):572-585. doi:10. 1080/15374416.2011.581613

13.Benjet C, Thompson RJ, Gotlib IH. 5-HTTLPR moderates the effect of relational peer victimization on depressive symptoms in adolescent girls. J Child Psychol Psychiatry. 2010;51(2):173-179. doi:10.1111/j.1469-7610.2009.02149.x

14.BDNF gene: MedlinePlus Genetics. https://medlineplus.gov/ genetics/gene/bdnf/ (accessed Apr 8, 2021).

15.Park, C.-hyun; Kim, J.; Namgung, E.; Lee, D.-W.; Kim, G. H.; Kim, M.; Kim, N.; Kim, T. D.; Kim, S.; Lyoo, I. K.; Yoon, S. The BDNF Val66Met Polymorphism Affects the Vulnerability of the Brain Structural Network. Frontiers in Human Neuroscience 2017, 11.

16.Vulturar, R.; Chiş, A.; Hambrich, M.; Kelemen, B.; Ungureanu, L.; Miu, A. C. Allelic Distribution of BDNF Val66Met Polymorphism in Healthy Romanian Volunteers. Translational Neuroscience 2016, 7 (1), 31-34.

17.Comasco, E.; Åslund, C.; Oreland, L.; Nilsson, K. W. Three-Way Interaction Effect of 5-HTTLPR, BDNF Val66Met, and Childhood Adversity on Depression: A Replication Study. European Neuropsychopharmacology 2013, 23 (10), 1300-1306.

18.Naninck, E. F.; Lucassen, P. J.; Bakker, J. Sex Differences in Adolescent Depression: Do Sex Hormones Determine Vulnerability? Journal of Neuroendocrinology 2011, 23 (5), 383392.

19.Heaney, J. Hypothalamic-Pituitary-Adrenal Axis. Encyclopedia of Behavioral Medicine 2013.

20.Halbreich, U.; Kahn, L. Role of Estrogen in the Aetiology and Treatment of Mood Disorders. CNS Drugs 2001, 15, 797-817.

21.Testosterone: Functions, deficiencies, and supplements. https:// www.medicalnewstoday.com/articles/276013 (accessed Apr 8, 2021).

22.Granger, D.; Shirtcliff, E.; Zahn-Waxler, C.; Usher, B.; KlimesDougan, B.; Hastings, P. Salivary Testosterone Diurnal Variation and Psychopathology in Adolescent Males and Females: Individual Differences and Developmental Effects. Development and Psychopathology 2003, 15, 431-449.

23.Ehrenfeld, T. The Three Types of Stress. Psychology Today. December 7, 2018.

24.Knott, D. L. Acute Stress Reaction https://patient.info/mentalhealth/stress-management/acute-stress-reaction (accessed Oct 26, 2020).

25.Low NC, Dugas E, O'Loughlin E, D. Rodriquez, G. Contraras, M. Chaiton, and J. O'Loughlin. Common stressful life events and difficulties are associated with mental health symptoms and substance use in young adolescents. BMC Psychiatry. 2012; 12:116. Published 2012 Aug 17. doi:10.1186/1471-244X-12-116

26.Mufson, L.; Dorta, K. P.; Wickramaratne, P.; Nomura, Y.; Olfson, M.; Weissman, M. M. A Randomized Effectiveness Trial of Interpersonal Psychotherapy for Depressed Adolescents. Arch. Gen. Psychiatry 2004, 61 (6), 577-584.

27.Stroud, K. Stressful Life Events and Major Depression.

28.Brockie, T. N.; Dana-Sacco, G.; Wallen, G. R.; Wilcox, H. C.; Campbell, J. C. The Relationship of Adverse Childhood Experiences to PTSD, Depression, Poly-Drug Use and Suicide Attempt in Reservation-Based Native American Adolescents and Young Adults. Am. J. Community Psychol. 2015, 55 (3-4), 411421.

29.Schilling, E. A.; Aseltine, R. H., Jr; Gore, S. Adverse Childhood Experiences and Mental Health in Young Adults: A Longitudinal 
Survey. BMC Public Health 2007, 7 (1), 30.

30.Bethune, S. American Psychological Association Survey Shows Teen Stress Rivals That of Adults https:/www.apa.org/news/press/ releases/2014/02/teen-stress (accessed Oct 26, 2020)

31.Jayanthi, P.; Thirunavukarasu, M.; Rajkumar, R. Academic Stress and Depression among Adolescents: A Cross-Sectional Study. Indian Pediatr. 2015, 52 (3), 217-219.

32.Cole, D. A.; Ciesla, J. A.; Dallaire, D. H.; Jacquez, F. M.; Pineda, A. Q.; Lagrange, B.; Truss, A. E.; Folmer, A. S.; TilghmanOsborne, C.; Felton, J.W. Emergence of Attributional Style and Its Relation to Depressive Symptoms. J. Abnorm. Psychol. 2008, 117 (1), 16-31.

33.Hankin, B. L. Stability of Cognitive Vulnerabilities to Depression: A Short-Term Prospective Multiwave Study.J. Abnorm. Psychol. 2008, 117 (2), 324-333.

34.Hankin, B. L.; Oppenheimer, C.; Jenness, J.; Barrocas, A.; Shapero, B. G.; Goldband, J. Developmental Origins of Cognitive Vulnerabilities to Depression: Review of Processes Contributing to Stability and Change across Time. J. Clin. Psychol. 2009, 65 (12), 1327-1338

35.Abramson, L. Y.; Seligman, M. E.; Teasdale, J. D. Learned Helplessness in Humans: Critique and Reformulation. J. Abnorm. Psychol. 1978, 87 (1), 49-74.

36.Hu,T.; Zhang,D.; Yang,Z.The Relationship Between Attributional Style for Negative Outcomes and Depression: A Meta-Analysis. Journal of Social and Clinical Psychology 2015, 34 (4), 304-321.

37.Abramson, L. Y. Hopelessness Depression: A Theory-Based Subtype of Depression. Psychological Review 1989, 96 (2), 358 372. https://doi.org/10.1037/0033-295X.96.2.358.

38.Rohde, P.; Stice, E.; Gau, J. M. Effects of Three Depression Prevention Interventions on Risk for Depressive Disorder Onset in the Context of Depression Risk Factors. Prev. Sci. 2012, 13 (6), 584-593.

39.Muris, P.; Schmidt, H.; Lambrichs, R.; Meesters, C. Protective and Vulnerability Factors of Depression in Normal Adolescents. Behaviour Research and Therapy 2001, 39 (5), 555-565.

40.Southall, D.; Roberts, J. E. Attributional Style and Self-Esteem in Vulnerability to Adolescent Depressive Symptoms Following Life Stress: A 14-Week Prospective Study. Cognitive Therapy and Research 2002, 26 (5), 563-579.

41.Rogers, C. R. On becoming a person 1961.

42.Alloy, L. B.; Liu, R.T.; Bender, R. E. Stress Generation Research in Depression: A Commentary. International Journal of Cognitive Therapy 2010, 3 (4), 380-388.

43.Auerbach RP, Ho MH, Kim JC. Identifying cognitive and interpersonal predictors of adolescent depression.J Abnorm Child Psychol. 2014;42(6):913-924. doi:10.1007/s10802-013-9845-6

44.Lee A, Hankin BL, Mermelstein RJ. Perceived social competence, negative social interactions, and negative cognitive style predict depressive symptoms during adolescence.J Clin Child Adolesc Psychol. 2010;39(5):603-615. doi:10.1080/15374416.2010.501284

45.Stevens, E. A.; Prinstein, M. J. Peer Contagion of Depressogenic Attributional Styles Among Adolescents: A Longitudinal Study. Journal of Abnormal Child Psychology 2005, 33 (1), 25-37.

46.Gladstone, T. R.; Kaslow, N. J.; Seeley, J. R.; Lewinsohn, P. M. Sex Differences, Attributional Style, and Depressive Symptoms Among Adolescents. Journal of Abnormal Child Psychology 1997, 25 (4), 297-306.

47.Hankin, B. L.; Abramson, L. Y. Measuring Cognitive Vulnerability to Depression in Adolescence: Reliability, Validity, and Gender Differences. Journal of Clinical Child E Adolescent Psychology 2002, 31 (4), 491-504.

48.Gender and health. https:/www.who.int/health-topics/ gender\#tab=tab_1 (accessed Apr 8, 2021).

49.Mood disorders: Depression and anxiety in teen girls https:// childmind.org/article/mood-disorders-and-teenage-girls/ (accessed Oct 26, 2020).

50.Bennett, D. S.; Ambrosini, P. J.; Kudes, D.; Metz, C.; Rabinovich, H. Gender Differences in Adolescent Depression: Do Symptoms Differ for Boys and Girls? J. Affect. Disord. 2005, 89 (1-3), 35-44.

51.Khesht-Masjedi, M. F.; Shokrgozar, S.; Abdollahi, E.; Golshahi, M.; Sharif-Ghaziani, Z. Comparing Depressive Symptoms in Teenage Boys and Girls. J. Family Med. Prim. Care 2017, 6 (4), 775-779.

52.Seeley, J. R.; Stice, E.; Rohde, P. Screening for Depression Prevention: Identifying Adolescent Girls at High Risk for Future Depression. J. Abnorm. Psychol. 2009, 118 (1), 161-170.

53.Nolen-Hoeksema, S. Gender Differences in Depression. American Psychological Society 2001.

54.Hankin, B. L.; Abramson, L. Y. Development of Gender Differences in Depression: Description and Possible Explanations. Annals of Medicine 1999, 31 (6), 372-379.

55.Hankin, B. L.; Mermelstein, R.; Roesch, L. Development of Gender Differences in Depression: Description and PossibleExplanations. Child Development 2007, 38 (1), 279-295.

56. Rudolph, K. D. Gender Differences in Emotional Responses to Interpersonal Stress during Adolescence. Journal of Adolescent Health 2002, 30 (4), 3-13.

57.Sansone RA, Sansone LA. Rumination: relationships with physical health. Innov Clin Neurosci. 2012;9(2):29-34.

58.Kato, T.Assessing Coping With Interpersonal Stress: Development and Validation of the Interpersonal Stress Coping Scale in Japan. International Perspectives 2013, 2 (2), 100-115. https://doi. org/10.1037/ipp0000002.

59.Kobak, R.; Ferenz-Gillies, R. Emotion Regulation and Depressive Symptoms during Adolescence: A Functionalist Perspective. Development and Psychopathology 1995, 7 (1), 183-192.

60.Avison, W. R.; Turner, R. J. Stressful Life Events and Depressive Symptoms: Disaggregating the Effects of Acute Stressors and Chronic Strains. Journal of Health and Social Behavior 1988, 29 (3), 253.

61.National Research Council (US) and Institute of Medicine (US) Committee on Depression, Parenting Practices, and the Healthy Development of Children; England, M. J.; Sim, L. J. Associations between Depression in Parents and Parenting, Child Health, and Child Psychological Functioning; National Academies Press: Washington, D.C., DC, 2009.

62.Weissman, M. M.; Wickramaratne, P.; Nomura, Y.; Warner, V.; Pilowsky, D.; Verdeli, H. Offspring of Depressed Parents: 20 Years Later. Am. J. Psychiatry 2006, 163 (6), 1001-1008.

63.Steinberg, L. We Know Some Things: Parent-Adolescent Relationships in Retrospect and Prospect. Journal of Research on Adolescence 2001, 11 (1), 1-19.

64.Sheeber, L.; Hops, H.; Davis, B. Family Processes in Adolescent Depression. Clinical Child and Family Psychology Review 2001, 4 (1), 19-35.

65.COMBRINCK-GRAHAM, L. E. E. Developments in Family Systems Theory and Research. Journal of the American Academy of Child E Adolescent Psychiatry 1990, 29 (4), 501-512.

66.Rawatlal, N.; Kliewer, W.; Pillay, B. J. Adolescent Attachment, Family Functioning and Depressive Symptoms. South African Journal of Psychiatry 2015.

67. Freed RD, Rubenstein LM, Daryanani I, Olino TM, Alloy LB. The Relationship Between Family Functioning and Adolescent Depressive Symptoms: The Role of Emotional Clarity.J Youth Adolesc. 2016;45(3):505-519. doi:10.1007/s10964-016-0429-y 
68.Shih, J. H.; Eberhart, N. K.; Hammen, C. L.; Brennan, P. A.

Differential Exposure and Reactivity to Interpersonal Stress Predict

Sex Differences in Adolescent Depression. Journal of Clinical

Child E Adolescent Psychology 2006, 35 (1), 103-115.

69.Allen, J. P.; Insabella, G.; Porter, M. R.; Smith, F. D.; Land, D.;

Phillips, N. A Social-Interactional Model of the Development of

Depressive Symptoms in Adolescence. J. Consult. Clin. Psychol.

2006, 74 (1), 55-65.

70.Armsden, G. C.; McCauley, E.; Greenberg, M. T.; Burke, P. M.;

Mitchell, J. R. Parent and Peer Attachment in Early Adolescent

Depression. Journal of Abnormal Child Psychology 1990, 18 (6), 683-697.

71.Joiner, T. E. Depression's Vicious Scree: Self-Propagating and Erosive Processes in Depression Chronicity. Clinical Psychology: Science and Practice 2000, 7 (2), 203-218.

72.Bowes, L.; Joinson, C.; Wolke, D.; Lewis, G. Peer Victimisation during Adolescence and Its Impact on Depression in Early Adulthood: Prospective Cohort Study in the United Kingdom. BMJ 2015, 350, h2469.

73.Klomek, A. B.; Marrocco, F.; Kleinman, M.; Schonfeld, I. S.; Gould, M. S. Peer Victimization, Depression, and Suicidiality in Adolescents. Suicide Life Threat. Behav. 2008, 38 (2), 166-180.

74.Cuijpers, P. A Psychoeducational Approach to the Treatment of Depression: A Meta-Analysis of Lewinsohn's "Coping With Depression" Course. BEHAVIOR THERAPY 1998, 29.

\section{Author}

Sia is a senior at Valley Christian High School in San Jose, California. She is interested in understanding how mental health affects youth. Through her website and magazine, Decompress, Sia learns alongside her users about mental wellbeing. She aims to study environmental science in the future. 